\title{
RENDICIÓN DE CUENTAS CON TRANSPARENCIA EN EL SECTOR PÚBLICO: ¿OTRA VEZ LO QUE EL VIENTO SE LLEVÓ? 1
}

Núm. 1 (2013), pp. 133-168.

José María Labeaga ${ }^{2}$, Antonio Ramiro ${ }^{3}$.

Recibido: Junio, 2013

Aceptado: Octubre, 2013

JEL Clasif: $\mathrm{H}_{5} \mathrm{O}, \mathrm{H} 83$

\footnotetext{
${ }^{1}$ Una parte de este trabajo se presentó en la VI Conferencia bienal de la Sociedad Española de Evaluación, Barcelona, Mayo 2009.

2 Department of Economic Analysis in the Universidad Nacional de Educación a Distancia, Madrid y UNUMERIT, University of Maastricht. jlabeaga@cee.uned.es

3 Tribunal Económico Administrativo Central, Ministerio de Hacienda y Administraciones Públicas, Madrid.
} 


\title{
Resumen
}

La rendición de cuentas es aún una práctica muy debilitada en el conjunto de las administraciones públicas. La transparencia, además, es uno de los principios de actuación administrativa menos desarrollado. El desarrollo de las actividades de evaluación de programas y políticas públicas puede ser un instrumento clave para propiciar una innovación relevante de los modos de dirigir el sector público. Si en los próximos años se produjese una definitiva institucionalización de la evaluación, quizás, llegaría a ser costumbre que, al final de una legislatura, los ciudadanos pudieran conocer, pormenorizada y documentalmente, para qué han servido sus impuestos durante el periodo legislativo agotado, de qué modo se han podido ir solucionando aquellos problemas y demandas sociales que justificaron la adopción de determinadas políticas públicas, decididas en cualquier nivel de gobierno, y qué costes se han producido para la obtención de los resultados alcanzados y según los objetivos propuestos. De esa manera, la evaluación habría servido para instituir definitivamente la rendición de cuentas. Al propio tiempo, se habría dado un paso decisivo en la aspiración democrática de la necesaria accesibilidad y transparencia respecto de los resultados alcanzados por las decisiones de los poderes públicos. En todo caso, en el actual contexto de crisis global, que también afecta a la tradicional concepción de las relaciones Estado/Sociedad, los cambios pretendidos debieran ser una ineludible responsabilidad de los gobernantes más innovadores y con mayor olfato para la conexión con los intereses de la ciudadanía, aunque, debemos reconocer, que constituyen un desafío de gran envergadura de las instituciones públicas en las próximas décadas. La enumeración y descripción de estos desafíos y de los requisitos necesarios para afrontarlos constituyen los objetivos de este trabajo.

Palabras clave: Transparencia; rendición de cuentas; políticas públicas; sistemas de evaluación.

\begin{abstract}
.
Accountability is still a weak practice in the public administration. Transparency, in addition, is one of the less developed principles for administrative activity. Development of public policies evaluation can be a key instrument to promote relevant innovation in the way public sector is managed. In the case that in the following years the institutionalization of evaluation takes place, it could perhaps be a usual situation that at the end of each legislature citizens know, in a detailed and documented way, the following information: how were their taxes invested during the previous legislative period, how were addressed and solved those problems and social claims which justified the adoption of certain public policies at any level of government, and which were the costs to finance the obtained results according to the proposed
\end{abstract}


objectives. Therefore, evaluation would have contributed to establish accountability definitively, while defining it as something more than just the daily practice of supervising institutions or the tributary experts or budgetary control. At the same time, a decisive step would have been made into the democratic aspiration of a necessary accessibility and transparency regarding the results reached through public authorities' decisions. In any case, the present context of global crisis also affects the traditional conception of the State-Society interrelations. The intended changes should not be just a chimera but an inescapable responsibility of the most innovating governors and those with greater ability to connect with the interests of citizenship, although we must admit that this issue constitutes a great challenge for public institutions in the next decades. The main objectives of this paper are to enumerate and describe these challenges and the necessary requirements to face them.

Key Words: Transparency; accountability; public policies; evaluation systems. 


\section{Introducción.}

Con el riesgo de contribuir a un sesgo simplificador, seguramente no ajustado a la realidad compleja y heterogénea de su profesión, quizá deberíamos iniciar este apartado preguntándonos: ¿qué han hecho los políticos a lo largo de las últimas décadas para merecer ahora la desconfianza ciudadana? Dentro de algunos años es posible que, llegándose al final de una legislatura, los ciudadanos conozcan, mucho más pormenorizada y documentalmente que hoy, para qué han servido sus impuestos durante el periodo legislativo agotado, de qué modo se han podido ir solucionando aquellos problemas y demandas sociales que justificaron la adopción de determinadas políticas públicas o qué costes se han producido para la obtención de los resultados alcanzados según los objetivos propuestos. O sea, se conocerá con profusión qué hicieron los gobernantes con el mandato (formal) del voto popular, si llega a institucionalizarse esa rendición de cuentas. 4

Si llegara a darse esa costumbre sobre la rendición de cuentas (que en términos coloquiales habría que interpretar como dar razón de aquello que un sujeto es responsable), ésta sería algo más que una práctica tan solo concerniente a los organismos fiscalizadores (como sucede con el Tribunal de Cuentas, que ya publicita en su Web los informes que realiza sobre las cuentas públicas), a los expertos tributarios o al control presupuestario. Se trataría de una práctica social que debiera caracterizar la relación entre el Estado y la sociedad y que, además, personalizándolo, afectaría a la ética democrática de quienes representan a la voluntad popular. De aquel modo, los mandatarios tendrían que explicarse ante el electorado a base de razones documentadas, lo que contribuiría a desinhibir a la ciudadanía con la cosa pública, a disminuir su altísima desconfianza y a aumentar su actual nivel de politización para la participación social.

Para compartir códigos con los lectores, y puesto que abundan las acepciones y no siempre se le da el mismo significado al término, al depender de qué perspectiva académica o personal se adopte para definirlo, entenderemos en este trabajo por "rendición de cuentas" una posición más cercana y relativa al concepto de la responsabilidad como es la siguiente: "la capacidad y deseo de quienes definen $y$,

\footnotetext{
${ }^{4}$ Es posible que a la vista de la Ley de Transparencia aprobada en septiembre de 2013 en el Congreso de los Diputados hayamos sido excesivamente optimistas en lo que deparará la rendición de cuentas en el futuro.
} 
fundamentalmente, aplican las reglas de la sociedad -incluido el ejecutivo en los diferentes niveles y funcionarios públicos- para responder a las exigencias del ciudadano. La responsabilidad y aplicabilidad son dos dimensiones críticas de la rendición de cuentas sustantiva y la rendición de cuentas real implica alguna forma de sanción -sea a través de las urnas, los procesos legales, organizaciones de control institucional o la divulgación a través de los medios-".5

Unos ciudadanos activos, precisamente, no sólo deben votar y elegir cada cuatro años, generalmente desconociendo los resultados, alcanzados o pretendidos, de las políticas desarrolladas por el gobierno de turno; esa ciudadanía, si aspira a ejercer sus derechos en libertad, o sea sintiéndose libre y no como un sujeto que es pasto para la manipulación por desinformación, debe ser exigente con los políticos que la representan y pedirles información sobre la administración de los resultados de las urnas. En tanto que así lo hagan, merecerán, con mayor motivo, conocer los impactos de la actividad pública y el grado exacto de responsabilidad de los políticos, de los gobernantes y gestores públicos, para poder demandar, a quien corresponda, que rindan cuentas de lo hecho ante quienes deben legitimarles o no con su voto.

Al mismo tiempo, los ciudadanos merecen que los poderes públicos les faciliten las razones suficientes y argumentos elaborados, con rigor metodológico e inteligibilidad precisa, que justifiquen la pertinencia o acrediten el resultado favorable del desarrollo de unas y no de otras políticas públicas; merecen asimismo respuestas, que deshagan entuertos sobre responsabilidades de los diferentes niveles de gobierno concernidos, a interrogantes lógicos para una consciente elección política, es decir, ¿de qué es responsable quién durante qué tiempo?, ¿cuál es la dimensión del problema a resolver y a quién afecta?, ¿está llevándose a cabo la política tal y como se diseñó y cuáles fueron los objetivos de la misma?, ¿qué razones justifican la no aplicación de una determinada política, prometida en el programa electoral, y en su lugar se pone en práctica una contraria?, ¿qué variables del contexto socioeconómico influyen en la marcha de los programas?, ¿cuáles son los impactos de la intervención pública finalmente

\footnotetext{
5 La definición se toma de Foresti, Sharma y Evans (2007), traduciendo el concepto de "accountability" empleado por O’Neil, Foresti y Hudson (2007). Otra acepción de rendición de cuentas más próxima a la aclaración sobre el contenido de aquello de lo que se es responsable, la tendríamos en la definición que, junto a la que se hace en inglés de "accountability" y en francés de "Responsabilité de rendre compte (Redevabilité)", encontramos también en castellano en OCDE (2007): "Obligación de demostrar que se ha efectuado el trabajo cumpliendo con las reglas y normas acordadas o de declarar de manera precisa e imparcial los resultados obtenidos en comparación con las funciones y/o planes encomendados. Esto puede exigir una demostración cuidadosa, que pueda defenderse incluso judicialmente, de que la labor realizada es congruente con los términos contractuales".
} 
implementada y cómo los perciben los beneficiarios?, ¿a qué colectivos se les resolvieron sus problemas?, ¿cuál es el coste incurrido en relación a los beneficios alcanzados?, ¿cuál hubiese sido el coste en relación a otras alternativas?, ¿qué soluciones se adoptan sobre qué problema no previsto y aparecido en la implementación de la política, para ir alcanzando cuánto y en qué plazo y con qué consecuencias?....).

No hay suficientes opiniones fundamentadas que, aquí y ahora, le expliquen a la ciudadanía, a través de los medios de comunicación, qué costes y qué resultados son previsibles de alcanzar con aquellas y no con otras medidas políticas, ora emprendidas, ora por desarrollar aún, ni mucho menos que nos detallen cómo se gasta y para qué fines el dinero en cada nivel de gobierno, de modo que llegáramos a poder comparar, alguna vez, cuáles son los resultados de la ejecución de las políticas públicas que le competen y cómo las gestionan los gobernantes nacionales, regionales o locales, así como qué nivel de calidad alcanzan los servicios prestados al ciudadano en su ámbito de responsabilidad (¿quién lo está haciendo más satisfactoriamente y cómo medirlo de modo consensuado sin recelos para, al menos, poder exigir en cada ámbito que se emulen a los mejores estándares de comportamiento gestor y no solo político?). Si evaluar y rendir cuentas no es habitual, evaluar comparando los resultados de las políticas entre diferentes instituciones, niveles de gobierno o territorios resulta, a día de hoy, una utopía.

En todo caso, como ya estudió Prats (2010), podríamos establecer algunos indicadores mínimos para constatar en el futuro el grado mayor o menor de rendición de cuentas de nuestro sector público; así, y sin ánimo de exhaustividad, podría analizarse en el futuro los aspectos relacionados con las siguientes variables para tal constatación:

- el establecimiento de defensores del ciudadano por ministerio y agencia.

- el nivel de compromisos y de ejecución de los mismos de acuerdo a las Cartas de Servicio.

- los mecanismos de autoevaluación de la calidad y benchmarking.

- los paneles de consulta permanente sobre la calidad de los servicios. 
- el sistema presupuestario, como sistema que asegure un retorno por rendimiento (dinero por resultados en outputs y outcomes), por lo que, por ejemplo, cualquier proyecto urbanístico o de infraestructuras importante debiera contar con una memoria de impacto ambiental.

- el monitoreo y evaluación del rendimiento interno y externo de las unidades gubernamentales (los expertos en nuevas fórmulas de participación aspiran a replicar el modelo para la participación y la rendición de cuentas, de forma que en cualquier formulación de política pública deba plantearse desde su origen qué canales de participación abre la misma y cómo se va a rendir cuentas de lo hecho una vez implementada).

- los sistemas de agencias con contratos-programa (o contratos de gestión) y su implantación e incidencia en la mejora de los servicios públicos.

- la gestión de riesgos y auditorías de riesgos establecidos y exigidos en las unidades con tal problemática.

- las organizaciones que disponen de unidades con sistema de contabilidad analítica de costes.

- los Códigos de Conducta.

- los futuros posibles contratos de los partidos con sus votantes.

En el resto del trabajo se argumenta cómo son y cómo debieran ser las propuestas políticas para que la evaluación de políticas públicas sea un hecho en España; se describe, además, la dirección que debe tomar el sector público bajo el enfoque de transparencia y rendición de cuentas, se enumeran los desafíos y las reticencias que suscita la puesta en práctica de una verdadera cultura de evaluación y se enuncian los buenos y malos usos de los resultados. El trabajo concluye con una discusión acerca de las condiciones necesarias para poner en marcha este importante aspecto del proceso de transparencia y rendición de cuentas. 


\section{La necesidad de información, discusión y justificación.}

En los últimos años estamos asistiendo, con mayor o menor participación o implicación individual, a un cursillo acelerado sobre finanzas internacionales, directrices económicas comunitarias y, en general, macroeconomía intermedia, cuyo contenido tradicionalmente parecía reservado solo para economistas. Los debates mediáticos sobrevenidos sobre austeridad, consolidación fiscal y financiación autonómica y, singularmente, sobre los efectos de la crisis económica y financiera global y las políticas impuestas o por la Comisión Europea (CE) o por la denominada troika, nos están permitiendo conocer algunas interioridades de los déficit de las cuentas públicas, sobre el supuesto y necesario rigor presupuestario, la eficiencia económica, los márgenes de endeudamiento, la prima de riesgo, los plazos ampliados o no para el ajuste del déficit, los desequilibrios estructurales, las repercusiones en el mercado laboral, los datos impactantes de las periódicas Encuestas de Población Activa (EPA), etc.

Es posible que en la construcción de escenarios económicos para la adopción de políticas públicas se estén desarrollando modelos robustos, rigurosos y adecuados, por parte de los expertos, sobre todo economistas, que trabajan para los gabinetes ministeriales o de los partidos políticos, generalmente desconocidos para el gran público, y es también posible que se estén administrando adecuadamente los recursos y flujos de información existentes, los datos macro y micro económicos, calculando el valor añadido a las múltiples interrelaciones entre actores públicos y privados y, especialmente, del ámbito de las finanzas internacionales, del mundo financiero y empresarial o de los organismos multilaterales. Podemos incluso suponer que muchas de las recetas políticas institucionales de los últimos años para acometer programas, supuestamente reformadores, con los que reducir los déficit e ir saliendo de la crisis, se apoyen en datos objetivamente idénticos, es decir los suministrados por los gestores de las cuentas y estadísticas públicas nacionales y las de los organismos internacionales, pero lo que es creciente es un devenido posicionamiento político europeo (en Francia e Italia, sobre todo si nos referimos a gobernantes europeos, pero también en España o en muchos otros países, incluidos los EE.UU., si hablamos de economistas prestigiosos que son críticos con la política económica imperante en la Unión Europea) con 
alternativas distintas a las sostenidas por las instituciones comunitarias, tanto referidas a un necesario crecimiento económico como a un modo distinto para afrontar las políticas de austeridad y su aplicación o dilación en el tiempo. Es decir, aunque muchas veces se utilicen idénticos datos objetivos del problema se poseen distintos enfoques para interpretar la polimorfa realidad o proponer sus soluciones; tales enfoques, obviamente, aumentan su tamaño de visión si incluimos en el diagnóstico las ideologías de los expertos que las usen, llegándose a proponer paradójicas soluciones con las supuestamente sostenidas por sus adscripciones o simpatías políticas (los hay que, por razones partidarias, defienden a la vez el intervencionismo con una mano y la desregulación con la otra, el estímulo al consumo y el ahorro familiar, el no endeudamiento en proyectos superfluos y la inversión pública en faraónicos ferrocarriles de alta velocidad para el uso de minorías privilegiadas, la economía productiva y la desregulación para las transacciones financieras especulativas.... y un largo etcétera). No nos debe extrañar, en consecuencia, que el ciudadano no haya asimilado bien los cursos acelerados que ha de tomar y, además de encontrarse sobrepasado, desconfía de unos y otros.

De ese modo, muchos son los que proponen y pocos los que explican en qué argumentos y con qué evidencias empíricas sustentan sus alternativas; asuntos como en qué cálculos se apoyan, o en qué intuiciones o certezas se basan para sostener cada opción para la solución de la crisis y en qué plazos alcanzarla, son temas desconocidos para la inmensa mayoría de los, a lo sumo, espectadores de los media que, con perplejidad o incredulidad, asisten a rifirrafes superfluos que no acaban de comprender. La racionalidad argumental y la pedagogía política no son armas muy habituales en el debate público, de modo que la ciudadanía pudiera implicarse a fondo en la defensa de las opciones políticas, a base de confrontar opiniones fundadas acerca del meollo de las políticas públicas que se han decidido o se desean aplicar. Quizá la ausencia de tal racionalidad tenga mucho que ver con el fuerte desapego y desconfianza hacia los partidos políticos y la mayor simpatía hacia plataformas sociales que se movilizan al margen de los partidos tradicionales, lo que probablemente explique gran parte de los índices de abstención electoral que ya se atisban en el estado de ánimo de los ciudadanos. 


\section{1. ¿Quo vadis sector público en relación con la evaluación?}

Pero, además de la retórica de los programas electorales (tan insuficientemente conocidos y actualmente tan poco valorados por el conjunto de los ciudadanos), tampoco escuchamos, salvo excepciones generalmente de algunos expertos académicos, voces públicas prestigiosas que argumenten, discrepando o no entre ellas, sobre un deseado e inaplazable cambio político, ahora con la crisis global más que nunca, para el desarrollo de nuevos modos de la acción de gobierno que incluyan obligatoriamente a las prácticas de evaluación de todas las políticas públicas emprendidas. ${ }^{6}$ Siendo la finalidad principal de la evaluación el aprendizaje y mejora de las políticas, es decir, proporcionar criterios racionales para la toma de decisiones en el ciclo de gestión de los programas, desde el diseño hasta la implementación y la obtención de resultados (no parece abundar tal característica en la política oficial, si nos atenemos a la escasa autocrítica pública sobre los negativos efectos de las políticas emprendidas), no es menos importante la utilidad fundamental que la evaluación puede desempeñar para la rendición social de cuentas.7

En 2007 se abrió una posibilidad de que la evaluación de políticas penetrara en la agenda discursiva de los políticos y, en consecuencia, de que se modificaran los actuales escasos hábitos de quienes dirigen el sector público, en todas sus variantes de gobierno, al haberse hecho efectiva la creación de un nuevo organismo (una Agencia Estatal) destinado teóricamente a la evaluación de las políticas públicas (la Agencia de Evaluación de Políticas y Calidad de los Servicios, AEVAL), organismo que se mantiene actualmente en el organigrama del Ministerio de Hacienda y Administraciones Públicas, aunque se prevé su reconversión con una nueva denominación dentro del

\footnotetext{
${ }^{6}$ Algún investigador ya ha contabilizado el indicador del número de veces que se menciona el término de "evaluación” en los programas electorales para, después, indagar cuántas de esas evaluaciones de las políticas propuestas se han realizado al cabo de un tiempo por expertos independientes y cuáles se han dado a conocer públicamente (ver Labeaga, 2013).

7 Según el Centro de Investigaciones Sociológicas (CIS), en los últimos años ha crecido espectacularmente el número de ciudadanos que tienen una confianza mínima en los partidos políticos; así, cuando se pregunta por los principales problemas que tiene España, un 2,8\% de los encuestados afirmaban que "los partidos políticos" en Septiembre de 1993, siendo el cuarto problema para un 31,4\% en Marzo de 2013 lo que, unido al 44,5\% que, como tercer problema, así lo valoraban respecto de "la corrupción y el fraude", pone muy en cuestión actualmente a las instituciones. Por otra parte, según el mismo Barómetro de 2013, en una puntuación que varía entre o y 10, los que peor nota obtienen son los partidos políticos $(1,8)$, el Gobierno $(2,4)$ y el Parlamento $(2,5)$.
} 
proyecto de Ley de Transparencia que se ha aprobado en septiembre de 2013 en el Parlamento y que actualmente está en tramitación en el Senado.

A pesar de que algunos sectores (singularmente obligados por las demandas de la $\mathrm{CE}$ en relación con los fondos comunitarios) han venido realizando algunas experiencias de evaluación de programas en la administración pública española (de desarrollo rural, de empleo, de salud, de educación, de medioambiente, de cooperación internacional al desarrollo, etc.), podemos afirmar que no solo han sido insuficientes sino que, además, no han sido conocidas públicamente, salvo alguna excepción (y al no publicitarse, ni siquiera en las Web oficiales, no existen para quienes se interesasen por ellas).

En materia de evaluación ex-ante de la calidad y el impacto normativo, los referentes en España resultan manifiestamente mejorables tanto en lo referido a su diseño legal como a la práctica administrativa cotidiana. En especial, se puede destacar la falta de un auténtico análisis económico (más allá del estrictamente presupuestario) y social de los proyectos normativos, así como una deficiente regulación y puesta en práctica de la participación ciudadana. Asimismo, creemos que en España carecemos de experiencias relevantes en la evaluación ex-post de las normas jurídicas. El conocimiento de su impacto real tras su aprobación y la evaluación de su eficacia a lo largo de su vigencia también constituyen ámbitos en lo que está prácticamente todo por hacer en nuestro país. Estos hechos que parecían claros antes de crear la AEVAL y así se señalaban en los informes que justificaban su creación, no han cambiado sustancialmente desde entonces. Es también generalizada la opinión de los especialistas de que no se ha dispuesto de herramientas suficientes para determinar la calidad del gasto en materia de resultados de una política pública, y ya no digamos en materia de constatar empíricamente los impactos de la misma, que quedan completamente circunscritos al ámbito académico.

De producirse el deseado cambio, al que antes aludíamos, en los modos de dirección del sector público, con el que incorporar en las prácticas cotidianas los sistemas de evaluación de programas y políticas, cuyos resultados fueran transparentes y dados a conocer periódicamente por las instituciones gubernamentales, estaríamos frente a una transformación profunda del principio de transparencia, del funcionamiento más tradicional de las administraciones públicas y del modo de su comunicación con la sociedad, que tanto ha cambiado de contexto en los últimos 
tiempos. ¿Tendrá viabilidad en los próximos años que se produzca progresivamente algún tipo de reinvención del gobierno que contemple las peculiaridades españolas y sea de carácter multipartidario, de modo que nos colocáramos en una buena posición para liderar nuevas y avanzadas maneras de entender hoy la democracia en el seno de la Unión Europea? Serán los partidos políticos los que protagonicen ese cambio o será la movilización social y la participación de la ciudadanía los que lo promoverán?.

$\mathrm{Al}$ hablar de transparencia nos estamos refiriendo (en función de la proximidad al punto de vista ciudadano) tanto a la perspectiva más macro de la misma (o de su ausencia), caso de los mercados financieros o de la financiación de los partidos o de los paraísos fiscales, como a las visiones más meso o más micro del comportamiento transparente en la gestión pública, como podrían ser, por ejemplo, la información sobre el destino final de un proyecto de cooperación al desarrollo aprobado en un ayuntamiento, ${ }^{8}$ o la información relativa a un proceso de selección de un profesional para la ejecución de un proyecto de obra pública o en el seguimiento y visualización on line por un particular del estado de tramitación de su expediente, a través de la Web del organismo oficial que lo gestione.

Además, somos conscientes de que mucho de lo que aquí solicitamos para nuestro sector público, sobre transparencia y rendición de cuentas, lo podríamos replicar y extender a una multitud de países relevantes en la esfera internacional, como, por citar un ejemplo de país dominante, se encargó de recordar el presidente Obama a sus conciudadanos en el discurso inaugural de su mandato (" $Y$ aquellos de nosotros que gestionemos el dinero público tendremos que rendir cuentas, gastar con sabiduría, cambiar los malos hábitos y hacer nuestro trabajo a la luz del día, porque solo así podremos restaurar la confianza vital entre un pueblo y su gobierno").

Descendiendo a nuestra peculiar realidad político-administrativa, la utilización de comparaciones pertinentes (utilizando el benchmarking) entre los servicios públicos de las diversas Comunidades Autónomas (CC. AA.), máxime cuando es de todos conocido que la puesta en práctica de algunas políticas se está realizando de modo diferenciado

\footnotetext{
${ }^{8}$ Citando el ejemplo de la transparencia en la gestión pública de la cooperación al desarrollo: ¿cuántas instituciones públicas informan en sus páginas Web con todo detalle sobre la gestión, costes y avances, de los proyectos de cooperación al desarrollo para países africanos o latinoamericanos? ¿No deben conocer los vecinos de un municipio cómo se ha gastado su ayuntamiento una ayuda al desarrollo y qué resultados finales se han conseguido con la misma? ¿Hay la suficiente presión social para que los gobernantes den la máxima información posible sobre esos gastos? ¿Favorecería la transparencia que se percibiera con nitidez que no haya habido actuaciones fraudulentas en la gestión de las ayudas al desarrollo?
} 
entre las mismas, no sólo podría ser una práctica que prestigiara y enriqueciera a los sistemas de evaluación como instrumento de aprendizaje y de confiabilidad para los decisores públicos, sino que contribuiría a la sana competencia democrática de la gestión pública entre Administraciones, que tratarían de emular con sus programas y servicios a las mejores prácticas de cada territorio. A la postre, ese modo de actuar incidiría positivamente en los resultados de las políticas de cada autonomía y en los beneficiarios de las mismas, influyéndose, de paso, en la cooperación y en el clima de confianza, con la correspondiente disminución de los actuales recelos, entre las CC. AA. y entre éstas y la Administración General del Estado (no sólo deberían asegurarse unos mínimos de nivelación de servicios entre Autonomías, sino que, en una lógica de ambición de superación, se debería aspirar a mejorar los niveles alcanzados, al no haber ánimo de lucro ni cuentas de resultados de por medio, con las prácticas -tan poco utilizadas-de transferirse informaciones, compartir conocimientos y experiencias - no solo de las positivas, sino, con autocrítica pública, incluyendo las informaciones y lecciones de aprendizaje sobre los malos resultados-, y con una actitud cooperante, programar objetivos comunes de mejora que beneficiasen al conjunto de la ciudadanía de cada territorio y, por ende, a todos los ciudadanos del Estado).

Quizá fuese radical sostener que debe existir una total transparencia sobre lo que sucede tras las bambalinas del escenario donde se adoptan las decisiones políticas. En todo caso, de modo más pragmático y posibilista, deberíamos aspirar a que, al menos, haya transparencia, sin ambages, sobre la gestión y los resultados e impactos de las intervenciones públicas, en definitiva de aquello que se decidió hacer por un gobierno, aunque nos quedáramos inicialmente sin conocer de momento las razones que justificaron tal decisión. Habría de promoverse un cambio para que, aprovechando algún flanco positivo para el aprendizaje de los efectos más perversos, en términos democráticos, de la actual crisis económica, los gobiernos afrontaran la mejora de sus propias habilidades o aptitudes para gobernar, perfeccionando su papel regulador con nuevas cualidades (de calidad democrática) para la rendición de cuentas, para la información pública y el ejercicio de la pedagogía política ante la ciudadanía, para abrir las puertas de las instituciones y permitir el acceso ciudadano a ellas, a través del ejercicio de la democracia participativa, para, en definitiva, desarrollar lo que, en el libro blanco de la gobernanza europea, se definen como principios de buen gobierno que, de tanto referenciarlos, retóricamente, parecerían ya que de hecho son una 
realidad, cuando en su devenir reglamentario y en el hacer diario se perciben todavía, por el contrario, con muchísimas más sombras que luces.

Lo cierto es que cada vez es mayor el consenso, desde casi cualquier perspectiva, sobre la importancia de la transparencia en el sector público y, sobre todo, en el actual contexto de crisis global, máxime cuando se ha venido produciendo un fuerte aumento del gasto público, muchas veces no destinado al público sino a las instituciones financieras, lo que, consiguientemente, ha aumentado la demanda de justificación de dichas intervenciones de los estados y de que se vele, públicamente, por la buena utilización de los recursos empleados.

\subsection{Las dificultades del camino y los desafios para vencerlas.}

En el contexto de las prácticas habituales de las administraciones públicas y con los actuales valores políticos y burocráticos frente a los sistemas de evaluación, el objetivo de desarrollo y mejora de las capacidades de gobierno se ve obstaculizado por las resistencias a asumir los nuevos valores democráticos que propugnan los sistemas de evaluación de programas y políticas públicas, de modo que todavía no está extendida la cultura proactiva que facilite la apertura y confianza para compartir datos e informaciones públicas. En muchos procedimientos de las administraciones públicas, no se termina de considerar efectivamente la necesidad de la participación social, a la que sigue viéndose no sólo como algo demasiado complejo e ineficaz, si no peligroso para el status quo de los responsables políticos. La responsabilidad y rendición de cuentas sobre lo que se hace en la gestión pública sigue infundiendo temor. Las cuestiones de eficacia se personalizan y se trata de evitar su valoración. Los resultados de las posibles evaluaciones a realizar se viven como una amenaza y no como una oportunidad para la mejora, lo que impide conocer la coherencia y efectividad de las políticas. Sigue existiendo una cultura, numéricamente nada desdeñable, que procura preservar zonas de opacidad en contra de la transparencia administrativa y política, aunque solo pretenda la defensa de intereses corporativos.

Con un razonamiento lógico podríamos decir que los profundos cambios sociales acaecidos hasta ahora exigirían la necesaria adaptación a los mismos de los poderes e instituciones públicas, por lo cual no debiera de mantenerse, sin cambios profundos, un modo de funcionamiento en el que solo las élites institucionales conocen todo lo preciso para tomar las mejores decisiones en nombre del interés de la colectividad. 
Empleando una terminología conceptual de los modelos de calidad de un servicio, probablemente, tras treinta años de democracia española, ya ha llegado un nuevo momento de la verdad para aumentar la calidad de la misma, de modo irrenunciable: el momento de la modificación de la forma de gobernar y dirigir las administraciones públicas, venciéndose a los comportamientos resistentes al cambio y aumentando los estímulos reales para incentivar la participación ciudadana en los asuntos públicos, y no sólo para que los ciudadanos españoles se preocupen por el qué hay de lo mío (tan legítimamente como lo hacen los responsables de cada territorio autonómico, cuando negocian el sistema de financiación con el Ministerio de Hacienda) sino para promover la propia y mejor defensa de la colectividad, a partir del uso de los mejores estándares de funcionamiento de la democracia, que parecen olvidarse en el fragor de los vaivenes del PIB, del endeudamiento y de la recesión económica, a pesar de las evidencias de la desafección ciudadana con los políticos.

Para que haya participación debe existir información suficiente que la aliente. Puesto que los poderes públicos deben ser públicos, o sea, ejercitar el imperio de su gobierno a la vista o de modo manifiesto para todos, es absolutamente imprescindible la publicidad de sus intervenciones, y esta información, sobre lo que se hace (cómo se hace y para qué), facilitará los cauces para que un ciudadano pueda preguntarse en qué, cómo, dónde y cuándo podrá participar y a quién exigir, en su caso, que lo haga mejor o, en el mejor de los supuestos, a quién agradecérselo si fueron positivos los resultados así percibidos. En esa línea, una mayor implicación de quienes dirigen las administraciones públicas, en cada nivel de gobierno, estatal, autonómico o local, tendría que asumir la apuesta por el fortalecimiento de la transparencia de las instituciones, de la publicidad de los procedimientos, de la aplicación de códigos éticos que contemplen la implicación de los servidores públicos para, con unos modos distintos de dirección de las personas que las motiven, conseguir de ellas que se comprometan seriamente con la calidad de los servicios públicos $\mathrm{y}$, definitivamente, se orienten al interés general y satisfacción de las demandas y necesidades sociales, sumándose finalmente, y sin temores, a una nueva cultura de evaluación con la que someter al escrutinio ciudadano a todas las intervenciones públicas.

Aunque por muchos decisores no se reconozca así, y a pesar de que está reglamentado que la gestión del gasto público y la programación presupuestaria deben sustentarse en el principio rector de la transparencia, éste, sin embargo, es todavía, 
evidentemente, uno de los principios de las actuaciones administrativas y gubernamentales manifiestamente mejorable, por no decir que de los principios más retóricos y menos desarrollados efectivamente, por mucho que sea un término frecuentemente utilizado en los programas de los partidos y en el discurso de muchos políticos. Actualmente, seguimos esperando como termina la tramitación de la Ley de Transparencia, siendo conscientes que el proyecto de Ley no ha sido precisamente un ejercicio de transparencia aunque ha sido mejorado algo en el Congreso posiblemente por presión de expertos y también por la presión mediática ejercida a la vista de los distintos acontecimientos sobre corrupción acontecidos.

Solamente enunciamos a continuación unos ejemplos respecto de los desafíos que, a nuestro juicio, debieran abordarse en la nueva Ley. Respecto de la accesibilidad a la información, deben favorecerse procesos simples que hagan disponible la información para el ciudadano común; sobre la legibilidad de la información, debe partirse por aceptar que, cuando está disponible (las tecnologías telemáticas hoy lo hacen posible), gran parte de la información está hoy en un formato y lenguaje que sólo son comprensibles para funcionarios y expertos; sobre la cultura del secretismo, hay que preguntarse qué porcentaje de Departamentos ministeriales u organismos públicos cumplen hoy con las obligaciones mínimas de transparencia activa y acceso adecuado a la información y a su reutilización (los investigadores universitarios tendrían mucho que decir sobre los obstáculos que se encuentran en el sector público para realizar su tarea y no parece que en el estado actual la nueva norma mejore la situación); sobre el patrimonio e intereses de autoridades públicas de los distintos poderes del Estado, incluidos los parlamentarios, debe abordarse valientemente el conocimiento público sobre incompatibilidades y control del conflicto de intereses; sobre la efectividad de la futura aplicación de la Ley, sea cual fuere su contenido, debiera preverse el tipo de consecuencias o sanciones que habrían de considerarse ante los posibles incumplimientos en facilitar el acceso a la información que, en cualquier caso, debiera estar reconocido como un derecho fundamental y parte inherente a la libertad de expresión. 


\subsection{Los valiosos intangibles de la transparencia y la necesidad de masa crítica ciudadana.}

Respecto del sector público, el concepto de transparencia alude internacionalmente a la apertura y claridad de las actividades de gobierno e institucionales para el escrutinio de la sociedad y de los grupos de interés. Se trata de una práctica democrática para facilitar el acceso de la ciudadanía a la información social, política y económica de las instituciones que, por ello, son accesibles y confiables, lo que, consecuentemente, facilita la mayor participación social en la toma de decisiones. Parece cada vez más evidente que la transparencia es una de las claves condicionantes del buen gobierno y que, además, así lo valoran los ciudadanos cuando otorgan más credibilidad (y, también parece, que más expectativas de apoyo) a los gobiernos transparentes que a los que no lo son tanto. Este es un gran valor que fortalece tanto la democracia interna como la credibilidad externa.

Se asume en el concepto de transparencia, teóricamente, que esa información de las instituciones debe ser pública, puesto que los ciudadanos tienen derecho a conocer la utilidad de las políticas públicas, así como el uso y destino dado a lo que pagan y cómo y quiénes se lo administran, revisando y analizando lo que deseen, y sin que existan espacios de oscurantismo (ausencia de difusión de la información), salvo en aquellas situaciones en las que se justifique la necesidad insoslayable de mantener la reserva, lo cual, en su caso, así debiera ser explicado. Aunque transparente signifique lo que es claro, evidente, que se comprende sin duda ni ambigüedad, si acudimos al diccionario de la Real Academia Española, la acepción político-administrativa más extendida se relaciona más con la información facilitada que con la comprensión del mensaje emitido.

Para la organización Transparencia Internacional, en aras de la transparencia, "se deberían buscar los medios para poder presentar periódicamente a los ciudadanos un conjunto o panel de magnitudes e indicadores básicos sobre distintos ámbitos y niveles de apreciación; en este sentido se deberían establecer unos indicadores o datos básicos relativos, por ejemplo, al endeudamiento que en cada momento tiene las administraciones públicas; o bien a la equidad intergeneracional, la cual no se suele respetar por parte de los gobiernos y de las disposiciones legislativas, por un cierto egoísmo de la generaciones actuales en detrimento de las generaciones futuras, a las que se suelen ir endosando deudas contraídas por las actuales generaciones; también 
se deberían presentar y publicar índices de retraso y calidad de la justicia, o relacionados con la contratación directa de obras públicas, o sobre los costes reales de las campañas electorales, etc. Todo ello, en fin, se debería poner a disposición de los ciudadanos, además de una forma clara y entendible por la mayoría de los mismos. Aparte de esta información de carácter operativo y económico, la transparencia del sector público debería hacerse extensiva asimismo al funcionamiento y los procesos de actividades que desarrollan los órganos e instituciones públicas a todos los niveles. Sería así necesario, para todo lo anterior, formular un panel de información básica e integrada para el ciudadano, que para no incurrir en costes innecesarios, y para agilizar la presentación y permanente actualización de los datos, debería estar disponible de una forma sencilla y directa en Internet."9 Para esta y respecto de un gobierno municipal, habría las siguientes áreas de transparencia a evaluar: información sobre la corporación municipal, relaciones con los ciudadanos y la sociedad, transparencia económico-financiera, Transparencia en las Contrataciones de Servicios y Transparencia en materias de Urbanismo y Obras Públicas. ${ }^{10}$

Es cierto que, en los últimos años, se ha venido avanzando en la transparencia de las Administraciones Públicas, como, por ejemplo, ha venido sucediendo con lo previsto en la nueva Ley de Contratos del sector público, ${ }^{11}$ en la que, con mayor fuerza que anteriormente, se desarrolla la transparencia de las actividades administrativas y decisoras de las instituciones, lo que, sin duda y aunque insuficiente, debemos estimar plausible para la iniciativa gubernamental y legisladora adoptada. Sin embargo, en un ejemplo de dirección contraria, muchas organizaciones públicas aún no han sido capaces, en sus prácticas cotidianas, de conseguir que no se obstaculice la circulación de información y se impida conocer cómo y con qué criterios se distribuyen los complementos de productividad en las retribuciones de sus funcionarios, a pesar de la transparencia prescrita por la Ley ${ }^{12}$ (tanto por la legislación anterior como por lo establecido en el EBEP, todavía no desarrollado por sus -nuevos- Estatutos de los

\footnotetext{
${ }_{9}^{9}$ Así lo manifiesta el presidente de la ONG Transparencia Internacional España, Lizcano (2005).

1o Puede consultarse el Índice de Transparencia de los Ayuntamientos españoles, elaborado por Transparencia Internacional de España, y cómo lo han medido a través de un conjunto de 80 indicadores, a partir de una evaluación de cinco áreas de transparencia:

http://www.transparencia.org.es/INDICE\%20TRANSPARENCIA\%20AYUNTAMIENTOS/INDICE\%20IT $\underline{\text { A.htm }}$

${ }^{11}$ Ley 30/2007, de 30 de octubre, de Contratos del Sector Público (BOE de 31/10/2007).

${ }^{12}$ Ley 7/2007, de 12 de abril, del (EBEP) Estatuto Básico del Empleado Público (BOE 13/4/2007).
} 
distintos niveles de Administración) y por lo que, además, se establece en dicha norma sobre el código de conducta de los empleados públicos, que deben actuar con arreglo a determinados principios, como el de transparencia, tal como queda recogido en los artículos 52 y 53 del citado EBEP.

Por ello, ¿qué valores o principios deben desarrollarse, modificando aquellos otros que vayan en sentido opuesto, para dirigir las administraciones públicas y ser transparentes con la ciudadanía, si a nivel interno, en los comportamientos de los propios servidores públicos, aún se recela de transmitir informaciones que clarifiquen los criterios directivos para la evaluación del desempeño y su ligazón con las retribuciones complementarias de los empleados? La transparencia, por tales razones, va ligada a la efectiva rendición de cuentas ante los ciudadanos, lo que abunda en que, como hoy sucede de forma generalizada en muchas administraciones públicas, no sólo deben disponer de datos e informaciones económicas las áreas presupuestarias o los gabinetes de planificación existentes en las mismas, sino que debe facilitarse la disposición pública y universal de su consulta, lo que además debiera ser imprescindible en una pretendida sociedad del conocimiento.

Aunque sólo sea una condición necesaria y no suficiente, debemos aceptar también que con la transparencia, junto a la rendición de cuentas y la mayor participación ciudadana en los asuntos públicos, se pueden combatir los fenómenos de corrupción ${ }^{13}$ y clientelismo (en sus diferentes versiones, protagonismos y grados de intensidad). Existen numerosos estudios que acreditan que la transparencia y el acceso a la información pública favorecen el combate contra la corrupción, reduciendo los espacios para ese tipo de prácticas, poniendo bajo la lupa ciudadana el escrutinio sobre la gestión pública y de las autoridades gubernamentales (de cualquier nivel de gobierno), permitiendo al mismo tiempo determinar los conflictos de intereses y haciendo posible la rendición de cuentas. ${ }^{14}$

\footnotetext{
${ }^{13}$ Así se establecía en el texto de la "Convención de las Naciones Unidas contra la corrupción" (ONU, 2010).

14 Para definir corrupción en este ámbito asumimos la definición de Bobbio (1988) que señala que la corrupción es "el fenómeno por medio del cual un funcionario público es impulsado a actuar de modo distinto a los estándares normativos del sistema para favorecer intereses particulares a cambio de una recompensa. Corrupto es, por lo tanto, el comportamiento ilegal de aquel que ocupa una función en la estructura estatal"... "La corrupción es un modo particular de ejercer influencia: influencia ilícita, ilegal e ilegítima. Esta se encuadra en referencia al funcionamiento de un sistema y, en particular, a su modo de tomar decisiones".
} 
Asimismo, desarrollar la transparencia supone propiciar la accesibilidad general a un tipo de información cualificada, a la que todavía no se nos ha habituado a los ciudadanos, cual sería la de las evaluaciones de las intervenciones públicas, con las que evidenciarse no sólo el modo de gestionar de las distintas administraciones sino también, lo que es aún más importante, las características y el alcance real del impacto social y económico de las políticas por ellas desarrolladas. Desgraciadamente, para una legítima aspiración de cualquier ciudadano crítico que aspire a la excelencia de su Administración, es aún muy insuficiente el número de políticos y gestores que se manifiesten públicamente, sobre la necesidad del cambio que, respecto al modo de concebir la evaluación de las políticas públicas, debieran asumir los distintos niveles de gobierno, y sobre la exigible transparencia en la rendición de cuentas de todos los poderes públicos, que vaya más allá de facilitar toda la información que les requieran el Tribunal de Cuentas o sus organismos homólogos autonómicos, para que éstos realicen el control y fiscalización externa de la gestión contable, económica y financiera de los distintos sectores públicos.

En relación con la transparencia, se ha llegado a afirmar que "democracia hoy es el gobierno del poder público en público", y como ya señalaba Bobbio, ${ }^{15}$ un Estado no puede denominarse a sí mismo democrático si no logra erradicar de su seno la existencia de "poderes invisibles", o decisores desconocidos por la opinión pública, añadiendo, además, que la apatía política se combate precisamente con la información y el llamamiento a participar. Algo similar preconiza Habermas, ${ }^{16}$ señalando que esos estados democráticos deben establecer un diálogo constante y propositivo con la ciudadanía, para que ésta pueda ejercer sus derechos democráticos a través de una deliberación racional, en la que se debata sistemáticamente con las instituciones. Además, se requieren capacidades de los gestores públicos que permitan liderar los cambios que se precisan, de forma que puedan comenzar las reformas, definir indicadores, establecer prioridades y periodicidades y conseguir apoyo para estos cambios que transformarán las instituciones pero que servirán en el medio y largo plazo para su justificación ante la ciudadanía. En definitiva, se necesita una nueva cultura de la evaluación, ${ }^{17}$ de la que deben impregnarse fundamentalmente los

\footnotetext{
${ }^{15}$ Bobbio (1996) se refería a la existencia de un doble Estado ("al lado de un estado visible existiría un estado invisible").

${ }^{16}$ Los conceptos de democracia deliberativa y educación dialógica están descritos en Habermas (1987).

${ }_{17}$ La expresión cultura de evaluación está recogida en UNICEF e IPEN (2006).
} 
servidores públicos, con la que fomentar la participación ciudadana en los asuntos públicos.

La crisis global presenta una gran oportunidad para comenzar esta tarea y a pesar de las tormentas o tal vez a causa de ellas parece que es ahora el tiempo de las mudanzas y no de las demoras, para avanzar sustancialmente en la profundización de tales conceptos por parte de las instancias gubernamentales, no debiendo convertirse esta gran crisis económica y financiera y sus consecuencias desastrosas, en una nueva ocasión perdida y frustrada para los intereses de las mayorías y las demandas de la ciudadanía, especialmente de la más activamente interesada en la gestión pública y tan alejada de la vida partidaria.

\subsection{Resultados y usos de la evaluación.}

Uno de los valores culturales más extendidos en nuestro sector público, como suele ocurrir en casi todas las latitudes burocráticas, es el del recelo ante la evaluación de políticas. En esto coinciden algunas investigaciones realizadas $^{18}$ que constatan (nosotros lo constatamos con la evidencia diaria) que subsisten temores profundos y concretos a la evaluación, por parte de políticos, directivos y funcionarios públicos. Por ejemplo, todavía es frecuente escuchar la manifestación de temores a que la evaluación sea utilizada para la represalia o el castigo profesional, a que con ella se resalten las debilidades y se hagan visibles los fracasos organizativos, a que los resultados de la evaluación de los expertos no se ajusten a determinada percepción de la realidad por parte de las cúspides directivas o políticas, a cómo y cuándo se utilizarán esos resultados y por quién y con qué intención, a que el riesgo asumido con la evaluación sea demasiado alto y el coste político, en términos electorales, no compense propiciar el esfuerzo realizado, y, en general, seguimos constatando un alto escepticismo con respecto a las bondades de los usos de las evaluaciones, estimándose que siempre habrá contextos o pretextos políticos que impedirán tomar en consideración los resultados de la evaluación o que, también, siempre habrá un espurio aprovechamiento de algún político de los resultados de una evaluación para utilizar en la contienda electoral, muy distinto a lo que sería un lógico proceso de aprendizaje o de rendición de cuentas que,

\footnotetext{
${ }^{18}$ Coincidiríamos, en el caso español, con las resistencias analizadas por diversos autores y con los principales temores de los funcionarios frente a la evaluación (Segone, 1998).
} 
en definitiva, son la esencia y los fines para los que se conciben los sistemas de evaluación de políticas públicas. ${ }^{19}$

Aunque sería conveniente que los recelos fueran decreciendo paulatinamente a través de la extensión de las mejores prácticas que, aunque aún muy minoritarias, vienen desarrollándose, poco a poco, en la Administración española, ${ }^{20}$ lo cierto es que aún hay muchos decisores, altos funcionarios $\mathrm{y}$ asesores que desconocen las potencialidades de la utilización de los resultados de los sistemas de evaluación. Numerosos expertos ${ }^{21}$ que han diagnosticado las finalidades que, alejadas del aprendizaje o la rendición de cuentas, han tenido algunos gestores públicos al encargar evaluaciones en distintas administraciones públicas del mundo, quizás confundiendo el pragmatismo gerencial con sus intereses estatutarios; así, se han justificado evaluaciones para demostrar a los demás que el programa que administran es acertado, o para determinar si dicho programa se desarrolla por los cauces predeterminados, o para valorar su eficacia en la satisfacción de las necesidades por las cuales fue formulado, o para la justificación de determinados gastos proyectados, o para delimitar mejor los costes relativos a los recursos humanos o financieros que se utilizan, o para apoyar la expansión del propio programa, o para comparar diversos tipos de programas en términos de eficacia o de eficiencia, o para satisfacer las demandas de los funcionarios responsables de las distintas actividades gerenciales que exigen pruebas de los efectos buscados por el programa, o para retrasar la decisión de poner en marcha una nueva política mediante la petición de otras evaluaciones y pruebas que justifiquen la efectividad de la misma, etcétera.

\footnotetext{
${ }^{19}$ A pesar de todos los problemas que tiene la universidad española, estos valores y temores no le son aplicables. Desde hace tiempo que los docentes e investigadores están sometidos a evaluación de sus dos actividades y, publicar los resultados de la investigación en revistas internacionales se consigue tras superar un proceso anónimo de evaluación por pares, proceso que resulta sumamente complicado en muchas ocasiones. La evaluación positiva de la actividad investigadora se obtiene tras documentar las publicaciones obtenidas a lo largo de un período de tiempo.

${ }_{20}$ Por ejemplo, con el auspicio de la Generalitat de Catalunya, y en régimen de consorcio con otros organismos públicos y centros de investigación privados, se estableció recientemente un Instituto de Evaluación de Políticas Públicas: www.ivalua.cat, en cuyo site se divulgan informaciones, metodologías y trabajos desarrollados en dicha materia. Asimismo, en la Web del Instituto de Estudios Fiscales (www.ief.es ), del Ministerio de Hacienda, se vienen publicando desde hace algunos años numerosos trabajos de investigación sobre evaluación de políticas, a través de sus distintas publicaciones.

${ }^{21}$ Así lo reproduce Moreno (1991), enumerando las razones principales por las cuales se realizan trabajos de evaluación de la puesta en vigor de políticas públicas en general y en relación a los usos explícitos espurios de los mismos.
} 
En todo caso, otros especialistas señalan que dependerá de cómo se gestionen distintos factores de las evaluaciones encargadas, para que se produzca una mayor o menor utilización de los resultados de dichas evaluaciones, siendo los aspectos más destacables "la oportunidad (la evaluación debe estar disponible cuando se tomen decisiones), la credibilidad (que no se ponga en duda la objetividad y solidez de la evaluación) y su diseminación o difusión (que las evaluaciones sean conocidas, y no archivadas como un documento histórico)", factor este último que tendría una "precondición” que sería "la transparencia del proceso evaluativo (la posibilidad de colocar las evaluaciones en Internet es una forma de facilitar la transparencia).”22

\section{3. ¿qué se necesita para que la evaluación de políticas sea una realidad en la sociedad del conocimiento?.}

\subsection{Las necesidades básicas en la sociedad del conocimiento.}

La incorporación de una sistemática evaluación de políticas y programas a la administración pública es todavía incipiente, y aún estamos alejados de decisiones colegiadas de gobierno con las que todos los Ministerios (o las áreas orgánicas correspondientes de las administraciones territoriales o locales) asumieran la obligación de desarrollar la evaluación en su modo cotidiano de funcionamiento, es decir, de demandar evaluaciones y encargar que se realicen para luego utilizar sus resultados, lo que sería un empuje decisivo para la mayor institucionalización de la evaluación. ${ }^{23}$

Pensamos que, como en otros países europeos, en España también se producirá la ambivalencia de que, por un lado, aumente la conciencia teórica respecto de la necesidad de aplicar lo aprendido con la evaluación, y, por otro lado, de que se posterguen las lecciones aprendidas, por intereses espurios o electorales, lo que supondría el desaprovechamiento coyuntural de las mismas por parte de los distintos gobiernos y administraciones públicas. El buen uso instrumental de las evaluaciones significaría un aprovechamiento continuo de los resultados de las mismas y una

\footnotetext{
${ }^{22}$ Tomado de Feinstein (2007).

23 Un ejemplo de una decisión centralizada de gobierno sobre políticas de evaluación podemos encontrarlo en Treasury Board of Canada Secretariat (2001).
} 
ampliación sobrevenida de conocimientos para aquellos poderes y, en el supuesto contrario de la no utilización por parte de los decisores, estaría significando una ineficiencia poco justificable en el marco de la rendición de cuentas al Parlamento o a la sociedad que toda esfera gubernamental debe realizar.

Por ello, con la institucionalización de la evaluación de las intervenciones públicas hay que promover, de modo prioritario, la progresiva e inevitable utilización de las evaluaciones pues, de no hacerse así, se resquebrajaría la confianza en las finalidades de las mismas, no contribuyéndose con la inhibición a la extensión de los valores plausibles de la cultura de evaluación que es asunto de gran calado en las administraciones europeas y especialmente de las mediterráneas, en orden a la consecución de una mayor legitimidad social de la acción pública. La cultura, y por supuesto las prácticas, de medición de los resultados por las organizaciones y decisores públicos exige la consideración de la evaluación como una herramienta que trasciende del mero control de los recursos públicos gestionados y que debe servir, aunque no solamente, para responder si lo que se ha realizado se ha hecho según lo previsto en el programa de intervención pública que lo sustenta. La evaluación, además, debe permitir preguntarse por el modo en que se produjo el diseño, la puesta en marcha y el despliegue de la política, y facilitar el mejor aprovechamiento de sus resultados para la mejora de la gobernanza.

Por tanto, la evaluación debe constituirse como una herramienta utilizada por todos los niveles de gobierno, y un arma potente de vinculación de la teoría a las prácticas gubernamentales y administrativas, a la vez que se convierta en la mejor oportunidad para mejorar los usos de la potencialidad de las herramientas empleadas en el análisis de la realidad de las políticas. Sin embargo, para que los decisores lo apliquen, no basta con que los evaluadores presenten unos informes aparentemente buenos, si no se ha tenido en cuenta las experiencias de conocimiento internacionales. El desarrollo de la sociedad del conocimiento ha traído consigo una rápida acumulación de información pero, en general, no se produce todavía una eficaz gestión del conocimiento acumulado a fin de que las organizaciones gubernamentales no asuman meras actitudes reactivas o se vean desbordadas por la sucesión de acontecimientos sobre los que no tienen previsto la mejor manera de afrontarlos. 
La presión ciudadana sobre los Gobiernos ha venido creciendo en los últimos años; se pide cada vez más eficacia y mayor y más pronta reactividad de los Gobiernos ante los problemas complejos que van presentándose en el mundo globalizado. Hoy cabe acumular mucha información sobre la gestión de problemas similares en cualquier parte del mundo, pero a la vez esa acumulación informativa exige de analistas que, gestionando el conocimiento, faciliten, por un lado, la no inhibición de los gobiernos en la toma de decisiones y, por otro lado, que éstas se adopten con el máximo de valoraciones que quepan realizar interaccionando de modo sinérgico unas y otras informaciones de unas y otras latitudes e instituciones gubernamentales del planeta.

En la actualidad cabe el análisis sincrónico de multitud de informaciones, de cientos de conocimientos acumulados en potentes bases de datos, en orden a la mejor gestión de las políticas públicas, escuchando las voces de los afectados, incluso, en tiempo real, y no demorando los estudios para fechas ulteriores, sino produciendo juicios que den respuesta a las demandas sociales en un tiempo relativamente corto. Por ello, no resulta deseable que se desaprovechen las lecciones de las evaluaciones remitiendo su utilización a futuras fechas que, habitualmente, nunca llegan a suponer un mejor contexto para ser aplicadas.

Sin embargo ha existido un antes de lo que proponemos que puede marcar el futuro de la evaluación. Antes, un gestor público solicitaba un estudio y se tardaba mucho tiempo en facilitárselo aunque le era entregado un amplio informe con multitud de páginas e infinidad de cuadros, datos y cifras, la mayor parte de las veces ininteligibles para el gestor profano en la expertisse evaluativa. Antes, esos denominados informes de evaluación tenían un único destinatario. Ahora, tras preguntarse por los usos acaecidos, los mejores gestores públicos quieren en el momento oportuno disponer de ese informe que precisan para poder tomar decisiones rápidas, fundadas y rigurosas, para lo que exigen informes muy sintéticos, con el máximo de datos interaccionados y capaces de tener en cuenta todos los conocimientos posibles sobre el problema a resolver. Ahora, los usuarios de la evaluación son múltiples, pues múltiples son los stakeholders de la misma. Ésta no sólo se realiza para el gestor público que la encarga, sino para ser almacenada, también, en generosas bases de datos que puedan ser compartidas por muchos otros usuarios de la misma.

El antes no nos sirve para el ahora y, es por ello que hoy, además, los evaluadores deben hacerse muchas más preguntas que hace algunos años, y deben cuestionar y reflexionar sobre los intereses heterogéneos de los diversos stakeholders, no olvidando los usos mediatos e inmediatos que se harán del contenido de las evaluaciones. Por otra 
parte, la complejidad de la actual sociedad, la velocidad a la que se producen los cambios, la capacidad de acceso a información de forma más rápida, la existencia de multitud de métodos para evaluar que pueden ofrecer contraste entre ellos, la capacidad de proceso de grandes volúmenes de información, etc. deben facilitar sobremanera toda esta labor y facilitar respuestas a problemas mucho más complejos y que requieren de perspectivas más amplias.

En la sociedad del conocimiento, y dadas las anteriores características de complejidad que afectan a problemas, actores, políticas y soluciones a adoptar, la evaluación puede ofrecer alto valor añadido estratégico a la gestión pública, en tanto que permitiría la interrelación de los múltiples elementos conectados entre sí, aunque aparentemente no lo estuvieran, cuya conexión, a través de la malla en la que se desarrollan las políticas públicas, puede constituirse en la explicación justificativa de sus resultados e impactos. La gestión del conocimiento sobre la evaluación devenida, además, exigiría en la actual sociedad la implementación de comunidades de práctica para el intercambio, para la transferencia, para el aprendizaje colectivo y organizacional, lo que, a su vez, exige que los gestores se planteen la inversión en esas nuevas líneas de conocimiento internacionales que, como pensamiento evolucionado y prácticas derivadas de multitud de experiencias, abundan hoy a nuestro alrededor y que siendo tan diversas abarcan asimismo a investigadores, analistas, actores sociales en fin de muchos sectores, públicos y privados, desde la esfera pública gubernamental a las ONGs o al conjunto de la sociedad civil.

\subsection{Un ejemplo por imposición y no por decisión.}

Para el sector público español algunos de los mandatos que provienen de las instancias europeas, incluso como imposiciones, serán decisivos para institucionalizar la evaluación de políticas públicas, sobre todo dependiendo de cómo se apliquen por la administración española, aunque ciertamente serán los usos que los decisores vayan dando a los resultados de las evaluaciones los que determinarán su mayor o menor institucionalización. Precisamente, como ejemplo del impulso (en este caso, incluso, habría que hablar de condición sine qua non, al menos de manera nominalista) que proviene de la $\mathrm{CE}$, vamos a comentar brevemente algunas aspectos de una institución que se va a crear mediante una Ley Orgánica que se aprobó en el Congreso el 10 de octubre y que sigue su tramitación en el Senado. Aunque habrá que analizar el contenido de la Ley Orgánica, ya hay numerosas voces que han puesto en duda la 
independencia del nuevo órgano, al conocer las explicaciones que dio el propio Ministro de Hacienda cuando lo anunció, a cuyo Ministerio se adscribirá. Parece, por tanto, que es un organismo más del propio ministerio al que la nueva institución debe examinar periódicamente.

En base a ese anuncio, y al informe que estudió el Consejo de Ministros, la nueva institución es una exigencia ${ }^{24}$ de la CE para mejorar la gobernanza económica y fiscal de la zona euro, habiendo así quedado recogida en el Programa Nacional de Reformas recientemente enviado a Bruselas. Se asegura, dentro de los cambios legislativos aprobados en los últimos años en pos de la disciplina presupuestaria, que la nueva Autoridad Fiscal será el mayor avance que España realizará en 2013, afirmándose también que dicha Autoridad estará dotada de independencia funcional y autonomía y contará con los recursos necesarios para el adecuado desarrollo de sus funciones, quedando plenamente garantizada su independencia. Sea como fuere, y tanto la Norma que se apruebe como las prácticas que realice arrojarán evidencias sobre su contenido, lo cierto es que un somero análisis de los Consejos Fiscales Independientes que existen en Europa (desde hace ya algún tiempo y, con la crisis y las políticas de austeridad presupuestaria, establecidos muy recientemente en algunos países como el Reino Unido, Irlanda, Portugal o Hungría) acreditan que dichos órganos realizan evaluaciones de políticas públicas. Nuestra cultura previa, el ministerio al que está adscrito y las voces discordantes sobre su funcionamiento e independencia no constituyen bases sólidas sobre las que poner demasiadas esperanzas.

Efectivamente, entre sus funciones, estos Consejos se encargan de la evaluación o seguimiento de la evolución presupuestaria y/o de las reglas fiscales, así como del análisis a largo plazo de sostenibilidad de las finanzas públicas (evaluaciones ex-ante, in itinere, $y$ ex-post). Aproximándonos a una definición amplia que sintetice la experiencia europea, y, de acuerdo con la información facilitada por la propia CE, ${ }^{25}$ podríamos definir a los Consejos Fiscales independientes como órganos públicos con

\footnotetext{
${ }^{24} \mathrm{El}$ establecimiento de una Autoridad o Consejo Fiscal independiente parte de una "Recomendación del Consejo Europeo sobre el programa nacional de reforma de 2012 de España y por la que se emite un dictamen del Consejo sobre el programa de estabilidad de España para 2012-2015" (Recommendation for a COUNCIL RECOMMENDATION on Spain's 2012 national reform programme and delivering a Council opinion on Spain's stability programme for 2012-2015. COM(2012) 310 final Brussels, 3-5-2012) y de acuerdo con el Memorando de Entendimiento sobre la Condicionalidad de la Política del sector financiero de Julio de 2012 (MoU) de la CE.

${ }^{25}$ La información sobre las "independent fiscal institutions" se encuentra en la web de la CE: http://ec.europa.eu/economy finance/db indicators/fiscal governance/independent institutions/index en.htm
} 
independencia funcional que, aunque varían sus actividades según el país de que se trate, elaboran estudios (evaluaciones, monitoreo o supervisión) de los resultados fiscales, coadyuvando a las previsiones macroeconómicas para el presupuesto y /o asesorando al Gobierno y/o al Parlamento sobre cuestiones de política fiscal. Estas instituciones se financian principalmente con fondos públicos y son funcionalmente independientes de tener una relación con las autoridades fiscales.

En algunos países, los Tribunales de Cuentas se podrían incluir en esta definición si sus actividades fuesen más allá del control contable y realizasen cualquiera de las tareas mencionadas anteriormente. En algunos Estados miembros europeos los Consejos son un instrumento para mejorar la toma de decisiones de política fiscal proporcionando análisis positivo y/o normativo, evaluaciones y recomendaciones en el ámbito de la política fiscal. En otros Estados, incluso, estas instituciones fiscales, denominadas de distinta manera, proporcionan previsiones macroeconómicas para la elaboración del presupuesto sin el sesgo de las previsiones gubernamentales; en ocasiones, de modo imparcial supervisan o evalúan la aplicación de los planes presupuestarios, el respeto de los objetivos y reglas presupuestarias, la sostenibilidad de las finanzas públicas o la orientación de estabilidad de las políticas fiscales, coadyuvando con ello al aumento de la conciencia social y política sobre los costes y beneficios de las medidas presupuestarias, tanto entre los responsables políticos como de los ciudadanos.

Aunque habrá que esperar, y no somos muy optimistas en el futuro de sus resultados, al establecimiento y primeros pasos de la nueva Autoridad Fiscal en España, lo cierto es que podría ser una palanca decisiva para el aumento de la transparencia fiscal y la rendición de cuentas. Una mayor transparencia de las finanzas públicas permite, al menos potencialmente, el debate democrático, racional y argumentado, entre Gobierno y Ciudadanía, sobre las políticas fiscales y sus resultados, facilitando la rendición de cuentas y la materialización de responsabilidades sobre la gestión y los impactos de las políticas y programas presupuestarios. Con la transparencia fiscal se fortalece la legitimidad social de las intervenciones públicas, al facilitarse el acceso y comprensión ciudadana (y de los contribuyentes) de las políticas macroeconómicas, así como el acceso a los mercados nacionales e internacionales de capital. Asimismo, la transparencia fiscal ayuda a detectar los riesgos de los escenarios en los que se implementan las previsiones fiscales, lo que facilita las respuestas y la anticipación a los problemas y condiciones económicas devenidas con nuevas medidas fiscales más oportunas que permitan mitigar la frecuencia e intensidad de las crisis. 
La transparencia fiscal se puede materializar a lo largo del proceso de elaboración presupuestaria, aunque discursivamente se haya considerado mayoritariamente que era más importante la transparencia en la fase de ejecución del presupuesto que, en este último caso, se asociaba también al modelo de control y seguimiento de la implementación de los programas presupuestarios, y en la última fase de obtención de resultados, en la que la transparencia se liga a las fórmula empleadas para la rendición de cuentas. Como consecuencia de formar parte de la propia elaboración o formulación de la política pública o programa gubernamental, es en esta fase iniciática cuando debiera iniciarse el proceso de transparencia, estableciendo canales de participación social, aunque, ciertamente, en esa primera fase el protagonismo suele estar casi monopolizado por la intervención de los partidos políticos que, con su actividad representativa, negocian y aprueban en los Parlamentos, según los equilibrios de las distintas fuerzas, los Presupuestos, siendo escasos los países o niveles de gobierno que han implementado nuevas vías para canalizar la participación directa de los ciudadanos en la formulación de las políticas.

\section{Reflexión final.}

Sintetizando lo anterior, parece evidente que, dependiendo del tratamiento que le asignen los gobernantes, la evaluación de las políticas públicas y la transparencia fiscal en España, en todos los niveles de gobierno, podrían dar un salto cualitativo de importancia con solo emular las mejores prácticas europeas en el establecimiento y desarrollo de organismos adecuados para ello.

Conocer cómo vienen implementándose los programas y políticas públicas, accediendo de forma transparente a los documentos que lo acrediten, permitiría superar cierta percepción determinista, aún existente, heredada del antiguo régimen y de los valores burocráticos más tradicionales, según la cual las administraciones públicas nunca podrán llegar a ser excelentes, por lo que los gobernantes de turno que las dirigen tampoco, por cuestiones electorales, llegarán a explicar con suficiente nitidez cómo lo están haciendo ni qué resultados están alcanzando.

Ahora bien, la evaluación de políticas y programas con la que realizar y emitir juicios y recomendaciones, basados en evidencias y contrastados empíricamente con las 
técnicas adecuadas, cuantitativas, cualitativas o mixtas, deben ser responsabilidad de evaluadores e instituciones que actúen con principios de independencia, que gocen de credibilidad y autoridad experta, para que no sean pasto del uso partidario y las disputas electorales, para que no se cuestione ni ponga en tela de juicio el contenido de sus evaluaciones, estudios o investigaciones, como ya sucede, por ejemplo, con la credibilidad de los estudios y cifras manejadas por el Banco de España, o con las fuentes de información de algunos organismos internacionales o con los informes tipoPISA de la OCDE, a los que ningún partido político ó gobernante osa poner seriamente en duda su rigor o fiabilidad metodológica. 


\section{Referencias Bibliográficas.}

Bobbio, N., I. Mateucci y G. Pasquino (1988), Diccionario de Ciencia Política”, ed. Siglo XXI, México.

Bobbio, N. (1996), El futuro de la democracia, FCE, México.

Centro de Investigaciones Sociológicas (varios años), “Barómetro del CIS”, Madrid http://www.cis.es/cis/export/sites/default/Archivos/Indicadores/documentos html/TresProblemas.html

Feinstein, O. (2007), “Evaluación pragmática de políticas públicas”, Información Comercial Española. Revista de Economía, 836, pp. 27-28.

Foresti, M., B. Sharma y A. Evans (2007), "Voz por la rendición de cuentas: los ciudadanos, el estado y la gobernabilidad realista”, Briefing Paper 31, London.

Habermas, J. (1987), “Teoría de la acción comunicativa” (tomo II), Taurus.

Heidenheimer, A. J. (1998), Topografía de la corrupción; investigaciones en una perspectiva comparativa.

http://www.unesco.org/issj/rics149/heidenheimer149.html

Heidenheimer, A. J. y otros (1989), “Corrupción Política”, en Political Corruption: A Handbook.

Labeaga, JM. (2013), “Transparencia y evaluación de políticas en España: lágrimas en la lluvia”, Boletín de AES, 77.

Moreno, L. (1991), "Evaluación y optimización de políticas públicas: el caso de la formación del profesorado", Documento de trabajo 91-03, Instituto de Estudios Sociales Avanzados, CSIC, Madrid.

Lizcano, J. (2005), “La transparencia como vector interdisciplinar de democracia, eficiencia económica y equidad social”, Revista Digital Encuentros Multidisciplinares, $\mathrm{n}^{\mathrm{O}} 19$. 
OCDE (2002), "Glosario de los principales términos sobre evaluación y gestión basada en resultados", Publicaciones de la OCDE, París.

http://www.oecd.org/development/peer-reviews/2754804.pdf

ONU (2010), “Convención de las Naciones Unidas contra la corrupción”, disponible en:

http://www.un.org/spanish/globalcompact/principes.htm

O’Neil, T., M. Foresti y A. Hudson (2007), “Evaluation of Citizens' Voice and Accountability: Review of the Literature and Donor Approaches”, London.

Prats, J. (2010), "Derecho al buen gobierno", en "La reforma de la AGE”, Jordi Sevilla (coordinador) Price WaterHouse Coopers y Lid Editorial, Madrid.

Segone, M. (1998), “Evaluación democrática”, Documento de Trabajo nº 3, UNICEF.

Treasury Board of Canada Secretariat (2001), "Evaluation Policy”, Ottawa.

http://www.tbs-sct.gc.ca/pol/doc-eng.aspx?id=12309

UNICEF e IPEN (2006), "Evaluation culture: a new approach to learning and change", en New Trends in Development Evaluation, Colección de Evaluation Working Papers.

http://www.unicef.org/ceecis/New trends Dev EValuation.pdf

Villoria, M. (1999), "El papel de la burocracia en la transición y consolidación de la democracia española: primera aproximación”, Revista Española de Ciencia Política, 1. 